\title{
The influence of sulfur addition on the hazard-type reaction of ilmenite ores with sulfuric acid
}

\author{
Maciej Jabłoński ${ }^{1}$, Krzysztof Lubkowski', Sandra Tylutka ${ }^{1}$, Andrzej Ściążko ${ }^{2}$ \\ ${ }^{1}$ West Pomeranian University of Technology Szczecin, Faculty of Chemical Technology and Engineering, Department \\ of Organic and Physical Chemistry, Al. Piastów 42, 71-065 Szczecin, Poland \\ ${ }^{2}$ Grupa Azoty Zakłady Chemiczne "Police” S.A., Kuźnicka 1, 72-010 Police \\ "Corresponding author: e-mail: klubkowski@zut.edu.pl
}

\begin{abstract}
The paper presents results of thermokinetic investigation of the hazard-type reaction of Norwegian and Australian ilmenite ores with sulfuric acid, modified by the addition of elemental sulfur, to increase the process safety in industrial conditions. In the reactions of both ilmenite ores the addition of sulfur caused a reduction of the thermal power generated in the reaction and a decrease in the value of the thermokinetic parameter $\Delta \mathrm{T}_{\max } / \Delta \tau$ for almost the whole range of initial concentrations of sulfuric acid. It was also found that the addition of sulfur to the reaction did not negatively affect the degree of ilmenite leaching. The interpretation of the obtained thermokinetic curves allowed to determine safe process conditions for both types of titanium raw materials.
\end{abstract}

Keywords: hazard-type reaction, ilmenite, titanium dioxide pigment, sulfur.

\section{INTRODUCTION}

In a number of chemical processes reaction kinetics should be controlled. It refers in particular to the reactions with a risk of uncontrolled run, called the hazard-type reactions. According to the definition, the hazard-type reactions are exothermic ones which can lead to thermal runaway, ${ }^{1,2}$. The reaction begins when the heat produced by the reaction exceeds the heat removed from the reactor. The excess heat raises the temperature of the reaction mass and increases the reaction rate, which increases the rate of heat production. An approximate criterion indicating the situation as dangerous is that the reaction rate - and hence the rate of heat generation - doubles with every ten degrees rise in temperature ${ }^{3}$. During the whole process, when the temperature rises, thermal runaway can occur. It happens because the rate at which heat is removed increases linearly but the rate at which heat is produced increases exponentially with temperature. Once the control of the reaction is lost, the temperature can rise rapidly leaving little time for correction. The reaction vessel may be at risk from over-pressurization due to violent boiling or rapid gas generation $^{4,5}$. One of the tools used to determine the process safety of hazard-type reactions is thermokinetics $^{6,7}$. It is a field of science that in its research area deals with the change of thermal power over time, using calorimetry as a research method.

An example of a technology with a high risk of uncontrolled progress of the reaction is the production of titanium dioxide pigments ${ }^{8-10}$. Titanium dioxide pigments are the most widely used white pigments ${ }^{\mathbf{1 1}}$, and they are commercially produced by the sulfate and chloride processes ${ }^{12,13}$. The main raw materials for sulfate process are ilmenite ores (mostly $\mathrm{FeTiO}_{3}$ with $\mathrm{TiO}_{2}$ content of 43-65\%) and/or titaniferous slags (metallurgy-enriched ilmenite ores with $\mathrm{TiO}_{2}$ content of $\left.70-80 \%\right)^{14}$, whereas in the case of chloride process - synthetic rutile (with $\mathrm{TiO}_{2}$ content of $\sim 92 \%$ ), produced from ilmenite ores in high-temperature hydrometallurgical leach process ${ }^{15}$.

In the sulfate process, described in detail elsewhe$\mathrm{re}^{14,16-18}$, ilmenites and/or slags are digested with highly concentrated sulfuric acid (80-95\%) to produce liquor containing mainly titanyl and iron sulfates. After the separation of solid $\mathrm{FeSO}_{4} \cdot 7 \mathrm{H}_{2} \mathrm{O}$, the liquor is hydrolyzed with water steam to initiate precipitation of hydrated $\mathrm{TiO}_{2}$ which is then calcined at $800-900^{\circ} \mathrm{C}$ to produce white solid $\mathrm{TiO}_{2}$. The first stage of this process, the reaction of ilmenite with sulfuric acid, is classified as a hazard-type reaction. The reaction is strongly exothermic and characterized by the possibility of a significant amount of gas emission to the atmosphere, highly corrosive environment, high temperature of the process, and the possibility of real thermal explosion as a result of uncontrolled rate of reaction'.

This reaction is a crucial step in the production of titanium dioxide pigments, because it affects the efficiency of obtaining the final product and its quality. Inadequately selected initial reaction conditions may result in incomplete conversion of the substrates (with large economic losses) and the risk of thermal explosion with potential fatalities, 19-21. The priorities in titanium dioxide production, i.e. the efficiency and safety of the process and the quality of the final product, may be achieved by appropriate selection of the reaction conditions. However, improvement in the process efficiency and safety can also be achieved by using appropriate additives ${ }^{22}$. Many attempts of using a variety of additives applied at different stages of titanium dioxide pigments production have been reported ${ }^{23-25}$. Nevertheless, there are no reports in the literature about the effect of any additives on the thermokinetics of this reaction.

The paper investigates the effects of the addition of sulfur on the reaction of ilmenites with sulfuric acid to increase the possibility of controlling the reaction rate. The main criterion for selecting an additive and the choice of sulfur for the reaction of ilmenite with sulfuric acid was to select an element that would not change the elemental composition of the substrates and would not adversely affect further stages of $\mathrm{TiO}_{2}$ production and the properties of the final product. The study aims to show that the addition of sulfur can reduce the thermokinetic parameters of the reaction, and thus reduce the risk associated with this reaction and increase the process safety. 


\section{EXPERIMENTAL}

Two types of raw materials were selected for investigation of the effect of sulfur addition on the thermokinetics of reaction of ilmenite ores with sulfuric acid. The raw materials were derived from deposits located in Norway and Australia, and they were found to be significantly different, both in phase and elemental composition ${ }^{26,27}$. Moreover, the deposits of Norway ilmenite are among the largest in Europe, while those of Australian ilmenite are among the largest in the world. The contents of the main elements present in both ilmenite ores were determined using the X-ray fluorescence method ${ }^{26}$ and are presented in the form of oxides in Table 1. X-ray absorption, diffraction and fluorescence measurements ${ }^{27}$ have shown that the main phases occurring in the Norway raw material are ilmenite $\left(\mathrm{FeTiO}_{3}\right)$, hematite $\left(\mathrm{Fe}_{2} \mathrm{O}_{3}\right)$, geikielite $\left(\mathrm{MgTiO}_{3}\right)$, enstatite $\left(\mathrm{MgSiO}_{3}\right)$ and $\mathrm{MnTiO}_{3}$, whereas in the Australian raw material the main phases are ilmenite $\left(\mathrm{FeTiO}_{3}\right)$, pseudorutile $\left(\mathrm{Fe}_{2} \mathrm{Ti}_{3} \mathrm{O}_{9}\right)$, hematite $\left(\mathrm{Fe}_{2} \mathrm{O}_{3}\right)$, geikielite $\left(\mathrm{MgTiO}_{3}\right)$ and $\mathrm{MnTiO}_{3}$.

Table 1. Elemental composition of Norwegian and Australian ilmenite ores

\begin{tabular}{|l|c|c|c|c|}
\hline Elements & $\% \mathrm{TiO}_{2}$ & $\% \mathrm{Fe}_{2} \mathrm{O}_{3}$ & $\% \mathrm{MgO}$ & $\% \mathrm{MnO}$ \\
\hline $\begin{array}{l}\text { Norwegian } \\
\text { ilmenite }\end{array}$ & 44 & 51.5 & 4.4 & 0.3 \\
\hline $\begin{array}{l}\text { Australian } \\
\text { ilmenite }\end{array}$ & 52.3 & 47.5 & 0.25 & 1.6 \\
\hline
\end{tabular}

Ilmenite ores were ground in a Pulverisette 5 planetary mill (Fritsch GmbH, Idar-Oberstein, Germany) to achieve about $92 \%$ of the product with a particle fraction below $40 \mathrm{~mm}$. The ground product was mixed with 1-5 wt\% of sublimed sulfur (Chempur, Poland, purity of 99.3\%) and then the sample was stirred mechanically for about 5 minutes. Samples of the mixture were taken for the thermogravimetry experiments with the use of a 1500C derivatograph (MOM, Mateszalka, Hungary). The studies were performed at temperatures from the range $30^{\circ}-1000^{\circ} \mathrm{C}$, at a heating rate of $3 \mathrm{~K} / \mathrm{min}$. The rest of the mixture was placed in a special container and after reaching a thermal equilibrium the samples were transferred into the calorimeter containing sulfuric acid. Thermokinetics experiments were performed according to the procedure described in detail previously ${ }^{28}$. Because of the specific nature of the reaction of titanium raw materials with sulfuric acid, i.e. corrosive environment of the reaction, the possibility of thermal explosion and the emission of gases into the atmosphere, a non-isothermal and non-adiabatic calorimeter was used in the experiments. The capacity of the calorimeter was $0.6 \mathrm{dm}^{3}$. The calorimeter was equipped with a heater, temperature sensor, feeder, and a safety valve ${ }^{26}$. The time constant and the heat transfer coefficient of the calorimeter were $257.5 \mathrm{1} / \mathrm{min}$ and $0.098 \mathrm{~J} /(\mathrm{K} \cdot \mathrm{s})$, respectively ${ }^{26}$. The study of the effect of sulfur addition on the reaction of ilmenite ores with sulfuric acid required the determination of the initial reaction conditions. Based on the previous experiments ${ }^{27}$ the initial conditions of the studied reaction were taken as follows: the initial temperature of $80^{\circ} \mathrm{C}$ and $90^{\circ} \mathrm{C}$ for Norwegian and $\mathrm{Au}-$ stralian ilmenites, respectively, the initial concentration of sulfuric acid $84 \%$ and the particle size distribution of the raw materials in the range of $88-92 \%$ particles passing $40 \mu \mathrm{m}$ sieves. The amount of sulfur added was at the level of $1 \%, 3 \%$ and $5 \%$ in relation to the mass of raw materials. The heat generated by the reaction mixture was recorded and then analyzed to determine the thermokinetic parameters of the reaction. After the completion of the reaction, the reaction mass was leached with deionized water, filtered, then the solution and the solid phase (leach residues) were analysed. No solidification of the reaction mixture was observed. Iron and titanium in the solution were determined by classical titration analysis ${ }^{29}$. On this basis, the degree of $\mathrm{Ti}$ leaching in relation to the total $\mathrm{Ti}$ content in the raw material (wt\%) was determined.

\section{RESULTS AND DISCUSSION}

The results of thermogravimetry measurements are presented in Fig. 1 and Fig. 2. The plots show the mass changes of the Norwegian and Australian ilmenite ores with and without the addition of sulfur, during heating up to $1000^{\circ} \mathrm{C}$. When heating both ilmenites without the addition of sulfur, an increase in mass is observed, initially, it is slow up to a temperature of about $400^{\circ} \mathrm{C}$, and then much faster to $800^{\circ} \mathrm{C}$. The increase in the samples' masses is due to the change in the level of iron oxidation that occurs in ilmenite ores ${ }^{26}$. The curves determined for both ilmenites with the addition of sulfur show a mass loss at $160-210^{\circ} \mathrm{C}$, followed by a slow increase in mass up to $400^{\circ} \mathrm{C}$, and then followed by a sharp mass increase up to $800^{\circ} \mathrm{C}$, as for the ilmenites without sulfur addition. Taking into account that the melting and boiling points of sulfur are $115^{\circ} \mathrm{C}$ and $444^{\circ} \mathrm{C}$, respectively, and the flash point of sulfur lies between $165^{\circ} \mathrm{C}$ and $210^{\circ} \mathrm{C}$, it can be concluded that the reduction in the sample mass, observed in the range of $160^{\circ} \mathrm{C}-210^{\circ} \mathrm{C}$, can be caused by sulfur oxidation. The results indicate that the presence of sulfur does not affect further changes occurring in the samples. No significant differences were found in the thermogravimetric curves of both materials. The shapes of experimental lines are similar and congruent changes occur in the same temperature ranges. The slightly larger weight loss observed for Norwegian ilmenite than for Australian one is a natural consequence of different composition of these materials.

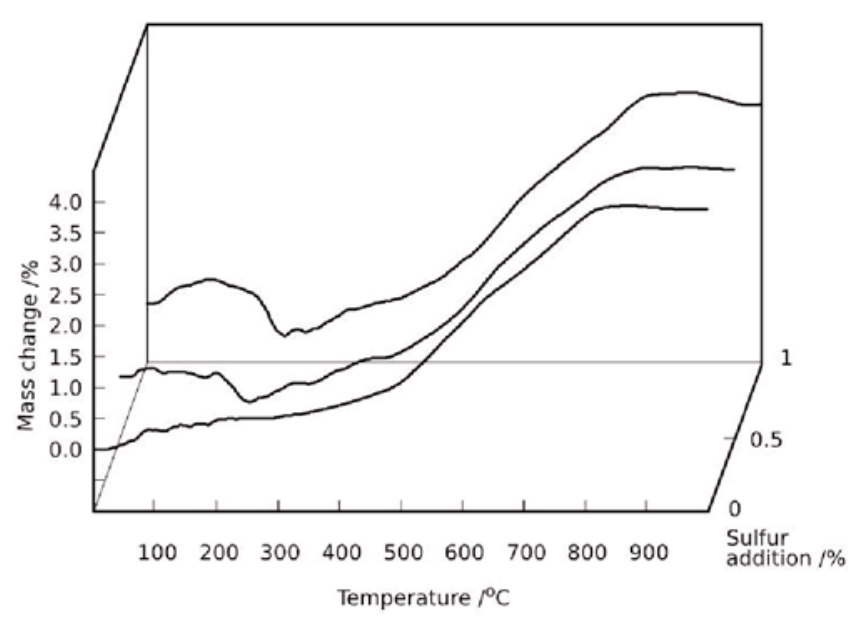

Figure 1. Mass changes in the heating processes of Norwegian ilmenite samples in the presence of different amounts of sulfur added 


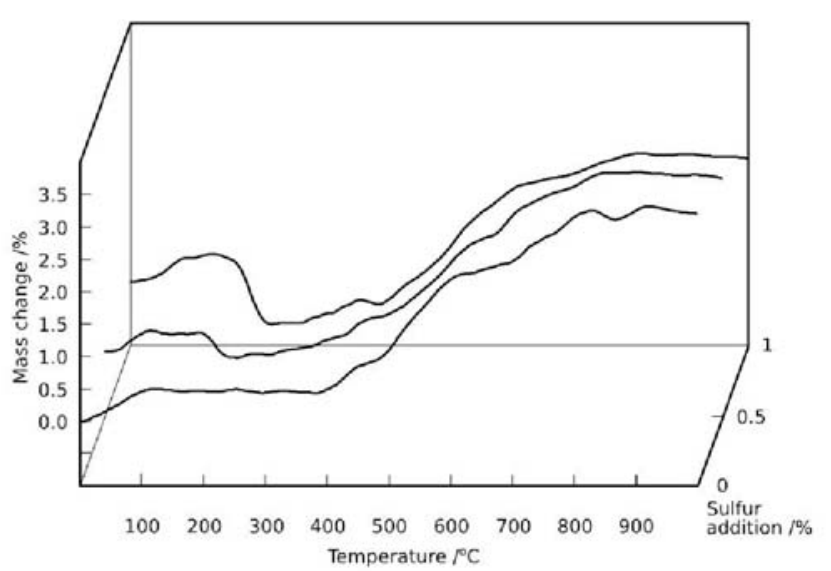

Figure 2. Mass changes in the heating processes of Australian ilmenite samples in the presence of different amounts of sulfur added

The influence of sulfur addition on the thermal power of the reaction of Norwegian and Australian ilmenite ores with sulfuric acid is presented in Fig. 3 and Fig. 4, respectively.

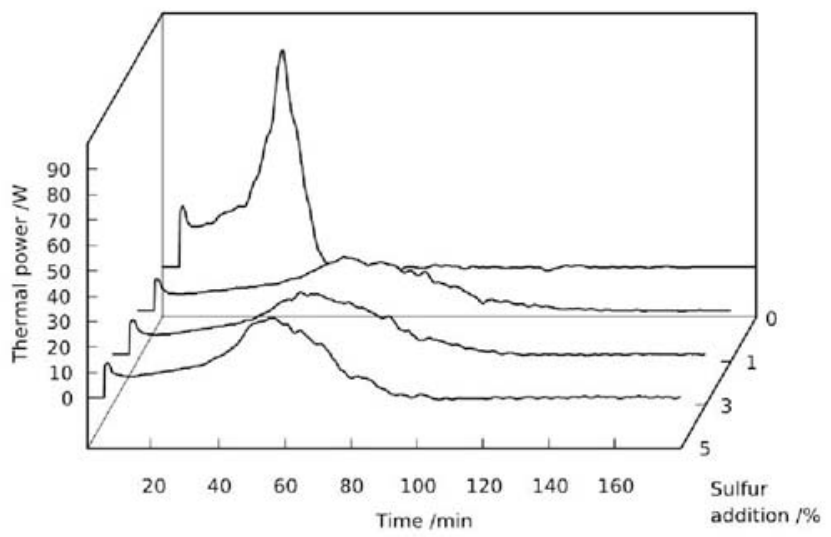

Figure 3. Changes in the thermal power of the reaction of Norwegian ilmenite ores with sulfuric acid in the presence of different amounts of sulfur

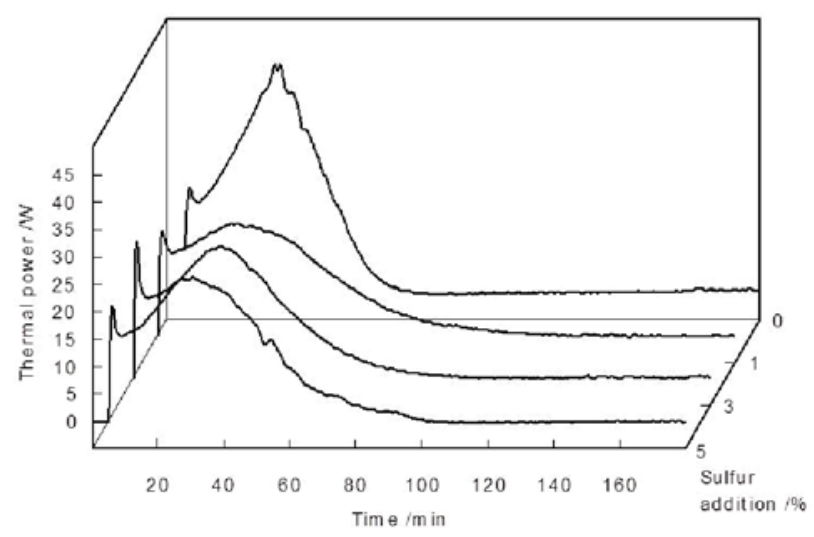

Figure 4. Changes in the thermal power of the reaction of Australian ilmenite ores with sulfuric acid in the presence of different amounts of sulfur

As follows from the presented results, the maximum thermal power in the reaction of Norwegian ilmenite with sulfuric acid (Fig. 3) was about twice as high as that in the reaction of Australian ilmenite (Fig. 4). This difference can be explained by the different compositions of both materials. Australian ilmenite contains greater amounts of iron(III) oxides with smaller enthalpy of creation in comparison with iron(II) oxide ${ }^{\mathbf{3 0}}$. A small addition of sulfur (1\%) to the reaction of Norwegian and Australian ilmenite ores with sulfuric acid caused a significant reduction in the maximum thermal power of the reaction. Moreover, the obtained thermokinetic lines show that after the addition of sulfur, the reaction proceeded more smoothly, and the time required to obtain the maximum thermal power was longer, especially for Norwegian ilmenite ores. Increasing the amount of sulfur in the reaction system to $3 \%$ and $5 \%$ did not significantly affect the maximum thermal power or reaction time.

Fig. 5 presents the results of studies of the effect of sulfur addition on the heat of reaction of ilmenite ores with sulfuric acid. For both materials, a significant reduction in the heat of reaction (from $10 \%$ to $15 \%$ ) is visible with the least amount of sulfur added (1\%). Increasing the amount of sulfur added to $3 \%$ and $5 \%$ did not further reduce the heat of the reaction.

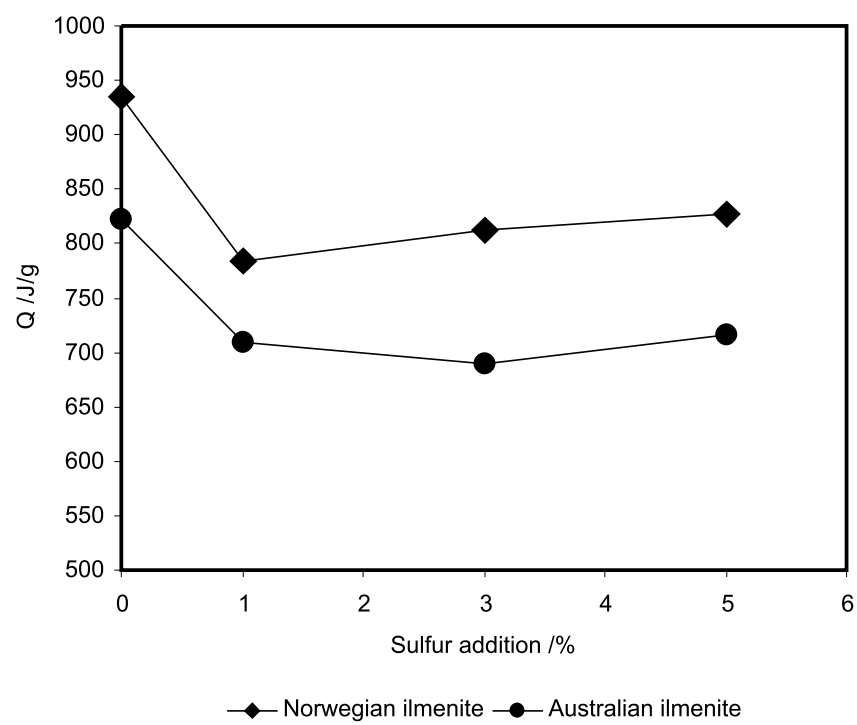

Figure 5. Heat of reaction of ilmenite ores with sulfuric acid as a function of the amount of sulfur added

A similar analysis was carried out for the kinetic parameter of the reaction, i.e. the apparent activation energy, which was assessed based on the kinetic model developed for this reaction in a liquid - solid heterogeneous system ${ }^{31}$. The following heat balance and the contracting core model equations ${ }^{\mathbf{3 1}}$ were used to estimate the apparent activation energy:

$\mathrm{W}(\mathrm{t})=\mathrm{dQ} / \mathrm{dt}=\Delta \mathrm{H}_{\mathrm{r}} \mathrm{d} \alpha / \mathrm{dt}=\mathrm{CdT} / \mathrm{dt}+\mathrm{G}\left(\mathrm{T}(\mathrm{t})-\mathrm{T}_{0}\right)(1)$

$\mathrm{d} \alpha / \mathrm{dt}=\mathrm{k}_{\mathrm{o}} \exp [-\mathrm{E} /(\mathrm{RT})] \mathrm{S}_{\mathrm{o}}(1-\alpha)^{2 / 3}$

where: $\mathrm{W}(\mathrm{t})$ - thermal power $(\mathrm{W}), \mathrm{Q}$ - heat amount generated during the reaction, $\Delta \mathrm{H}_{\mathrm{r}}$ - heat of the reaction, $\alpha$ - conversion degree, $\mathrm{C}$ - heat capacity of the calorimetric system $(\mathrm{J} / \mathrm{K}), \mathrm{G}$ - coefficient of heat loss $(\mathrm{J} / \mathrm{K} \cdot \mathrm{s}), \mathrm{S}_{\mathrm{o}}$ - initial surface of the solid $\left(\mathrm{m}^{2}\right), \mathrm{k}_{\mathrm{o}}-$ preexponential coefficient, $\mathrm{E}$ - apparent activation energy.

Fig. 6 shows the dependence of the apparent activation energy on the amount of sulfur addition for the reaction of ilmenite ores with sulfuric acid. As in the previous case (Fig. 5), a substantial decrease in the apparent activation energy can be observed already with the addition of $1 \%$ sulfur to the reaction environment. When increasing sulfur addition to the reaction, further changes in the apparent activation energy are quite small. 


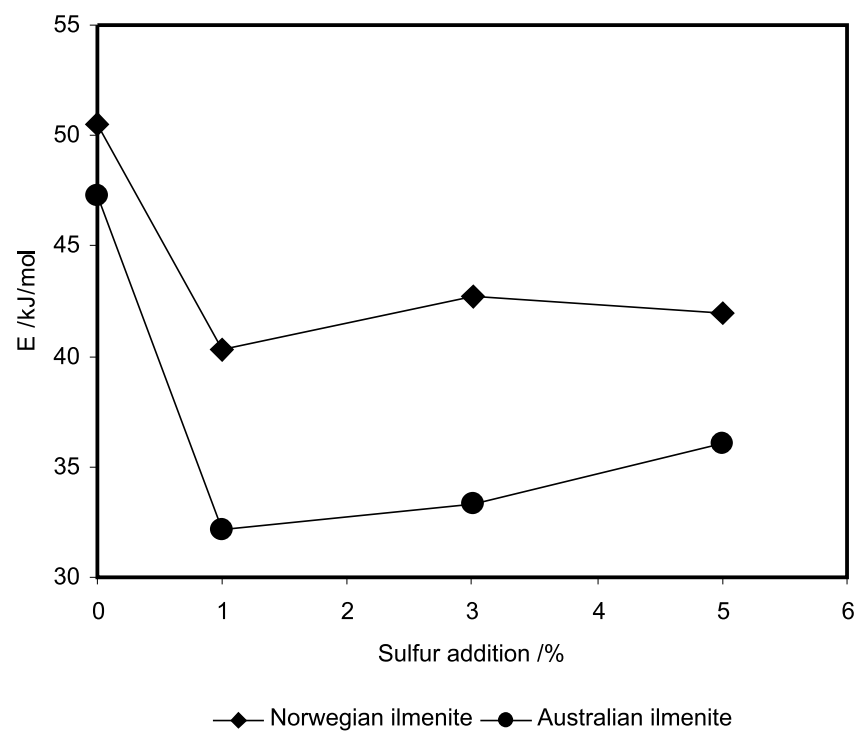

Figure 6. Apparent activation energy of the reaction of ilmenite ores with sulfuric acid as a function of the amount of sulfur added

An important parameter for evaluating the reaction thermokinetics is $\Delta \mathrm{T}_{\max } / \Delta \tau$, which can also be used for safety assessment and reaction optimization ${ }^{27}$. This parameter is defined as the ratio of the temperature increase (from the initial to maximum temperature of the reaction) to the time in which this temperature increase occurred. A high value of this parameter indicates the probability of thermal explosion, whereas a low value may indicate inadequate conversion of the substrates. Optimal reaction conversion is achieved under conditions when the parameter $\Delta \mathrm{T}_{\max } \Delta \tau$ has high values, but in this case, there is a danger of thermal explosion. The effect of the amount of sulfur addition on the change in the thermokinetic parameter $\Delta \mathrm{T}_{\max } \Delta \tau$ is illustrated in Fig. 7. Similarly, as in the previous cases, there is a pronounced decrease in the value of this parameter already upon the addition of $1 \%$ sulfur, which could have a crucial impact on the level of the process safety. With an increasing amount of sulfur added, further changes in the value of $\Delta \mathrm{T}_{\max } \Delta \tau$ are insignificant.

The influence of the amount of sulfur added to the reaction environment on the level of leaching of elements

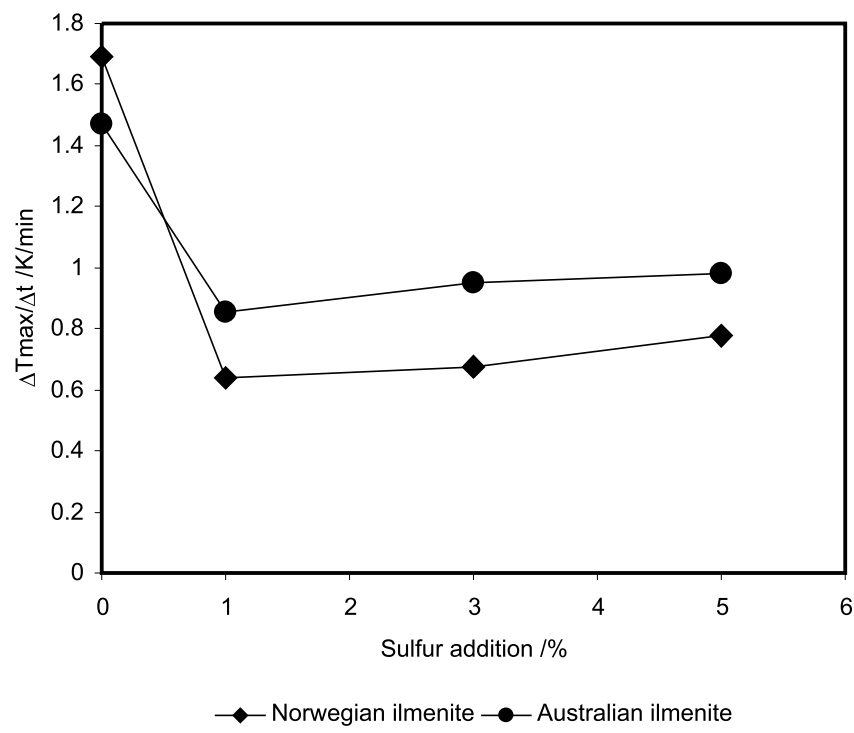

Figure 7. The impact of the amount of sulfur addition on the value of $\Delta \mathrm{T}_{\max } / \Delta \tau$ parameter from the reaction products is also very important. The effect of sulfur addition on the content of iron at the second and third oxidation degree after leaching of the reaction products is illustrated in Fig. 8. The presented data show that the concentration of iron at the second degree of oxidation in the solution distinctly increased relative to that after the reaction without the addition of sulfur. For both raw materials the maximum concentration of $\mathrm{Fe}^{2+}$ was observed after the smallest sulfur addition (1\%). With a further increase in the amount of sulfur, the $\mathrm{Fe}^{2+}$ concentration decreased in the case of Australian ilmenite.

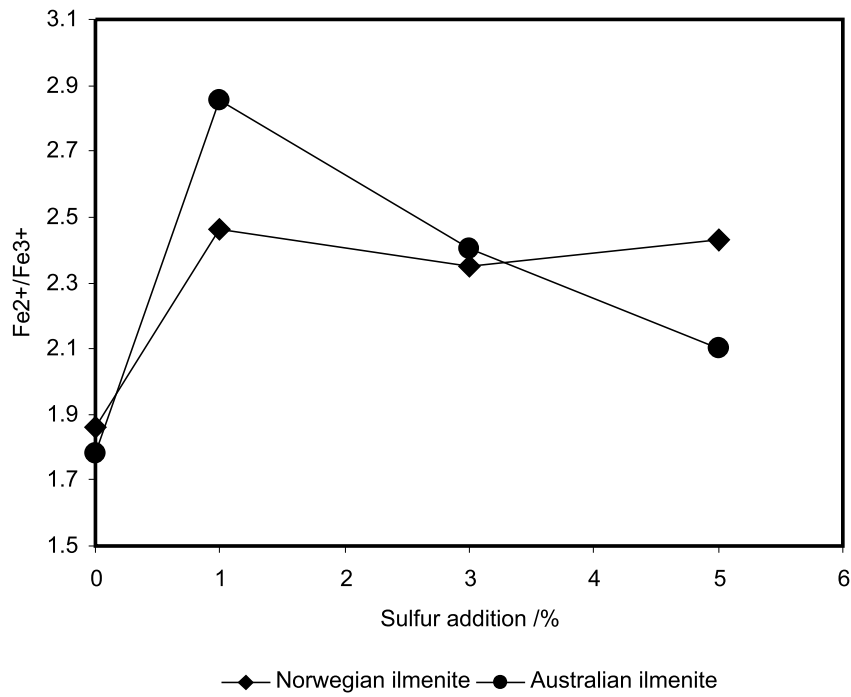

Figure 8. The content of $\mathrm{Fe}^{2+} / \mathrm{Fe}^{3+}$ after dissolving the reaction products as a function of the amount of sulfur addition

Taking into account the results obtained, another series of experiments were conducted to examine the effect of changes in the initial concentration of sulfuric acid in reaction with ilmenite, with the addition of sulfur at the level of 1\%. Fig. 9 and Fig. 10 show the effect of sulfuric acid concentration in the range from $82 \%$ to $90 \%$ on changes in the maximum thermal power for Norwegian and Australian ilmenite ores, respectively.

As indicated by the presented results (Fig. 9 and Fig. 10), the addition of sulfur reduces the maximum thermal power of the reaction in the whole range of sulfuric acid concentrations. The estimated measurement error was from $1 \%$ up to $6 \%$, for both ilmenites. A slightly different shape of the curves of the maximum heating power as a function of the concentration of sulfuric acid with and without the addition of sulfur can be also observed. The differences may indicate a significant influence of the sulfur addition on the reaction mechanism. The observed decrease in the maximum of thermal power for Norwegian ilmenite was from 0.5-2.6 $\mathrm{W} / \mathrm{g}$ to $0.2-1.7 \mathrm{~W} / \mathrm{g}$, and for Australian ilmenite from $0.4-0.79 \mathrm{~W} / \mathrm{g}$ to $0.1-0.49 \mathrm{~W} / \mathrm{g}$.

The likely cause of the influence of sulfur addition on the reaction thermokinetics is the blocking of active centers of ilmenite ores by sulfur, which may change its oxidation degree in certain temperature ranges. Because heat energy is released during the reaction, part of this energy changes the level of sulfur oxidation, which may affect the level of iron oxidation from $\mathrm{Fe}^{3+}$ to $\mathrm{Fe}^{2+}$. The confirmation of this phenomenon is a higher concentration of $\mathrm{Fe}^{2+}$ found in the solution after leaching, 


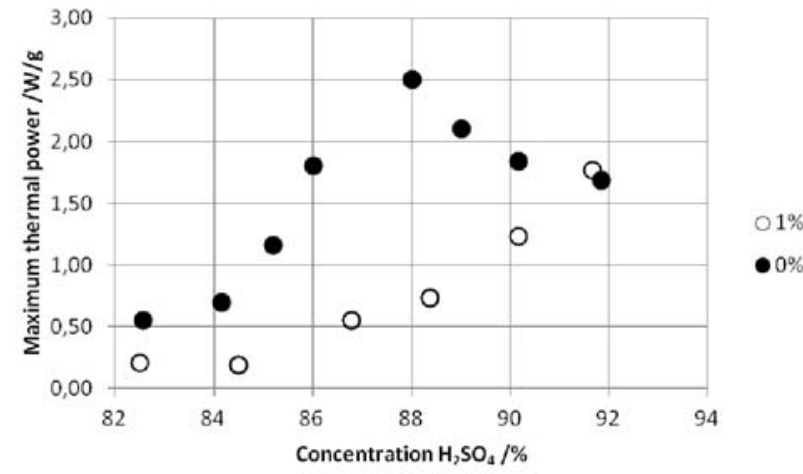

Figure 9. The impact of $1 \%$ sulfur addition on the maximum thermal power changes in the reaction of Norwegian ilmenite with sulfuric acid

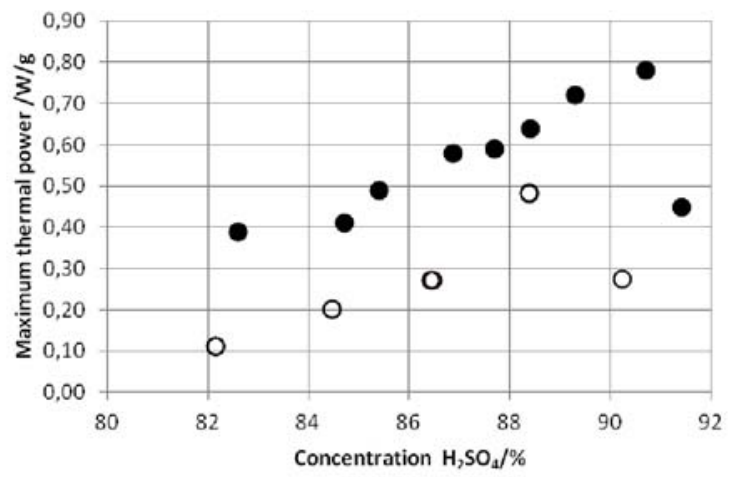

$01 \%$

- $0 \%$

Figure 10. The impact of $1 \%$ sulfur addition on the maximum thermal power changes in the reaction of Australian ilmenite with sulfuric acid

compared to that in the solution after leaching from the products of the reaction carried out without the addition of sulfur. Moreover, despite the lower level of the thermal effect of the reaction and the value of the apparent activation energy, the degree of the substrates conversion is at the same level as without the addition of sulfur.

The influence of $1 \%$ sulfur addition on the change in the parameter $\Delta \mathrm{T}_{\max } \Delta \tau$ is presented in Fig. 11 and Fig. 12. For both ilmenites, the sulfur addition to the reaction vessel resulted in the reduction in the value of $\Delta \mathrm{T}_{\text {max }} / \Delta \tau$. In the reaction of sulfuric acid with Norwegian ilmenite (Fig. 11), the value of $\Delta \mathrm{T}_{\max } / \Delta \tau$ decreased from $1.5-3 \mathrm{~K} / \mathrm{min}$ to $0.4-1.25 \mathrm{~K} / \mathrm{min}$, in the range of initial sulfuric acid concentrations of $82-88 \%$. Only the value of $\Delta \mathrm{T}_{\max } / \Delta \tau$ for $90 \%$ sulfuric acid remained at the same level as in the reaction without the additive. Addition of sulfur to the reaction of Australian ilmenite (Fig. 12), resulted in a reduction by half of the parameter $\Delta \mathrm{T}_{\max } / \Delta \tau$ in all tested concentrations of sulfuric acid in comparison to the reaction without the additive. As mentioned earlier, a high value of $\Delta \mathrm{T}_{\max } / \Delta \tau$ indicates the probability of thermal explosion, while its low value may indicate incomplete conversion of the substrates.

In addition to the influence on the thermokinetics of the reaction, it is also important to investigate the effect of sulfur addition on the reaction efficiency, in particular on the degree of $\mathrm{TiO}_{2}$ leaching. Fig. 13 and Fig. 14 present a comparison of the levels of $\mathrm{TiO}_{2}$ leaching in the reactions with and without sulfur addition, as a function of the sulfuric acid concentration. Fig. 13 shows the results obtained for the reaction with Norwegian

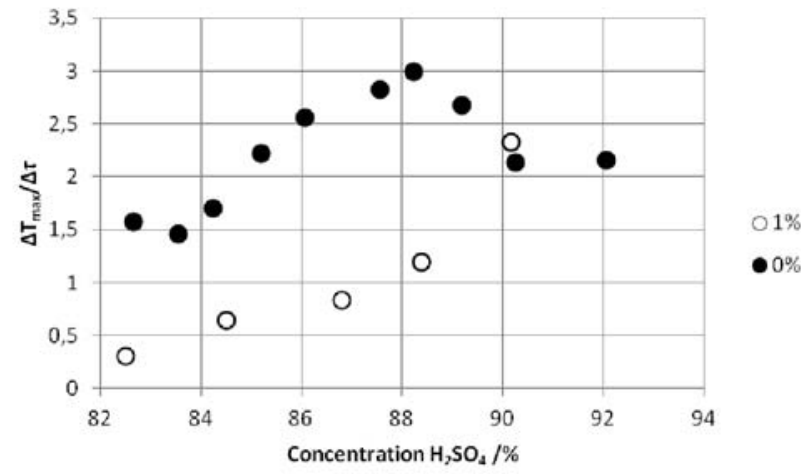

Figure 11. The impact of $1 \%$ sulfur addition on the safety parameter $\Delta \mathrm{T}_{\max /} \Delta \tau$ in the reaction of Norwegian ilmenite with sulfuric acid

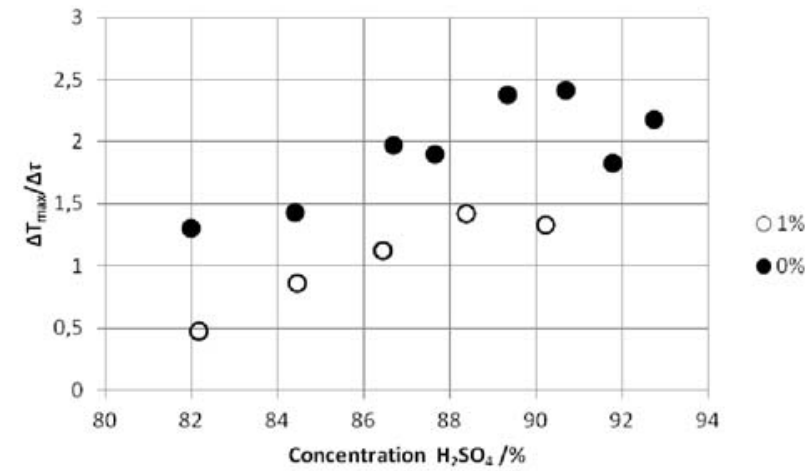

Figure 12. The impact of $1 \%$ sulfur addition on the safety parameter $\Delta \mathrm{T}_{\max } / \Delta \tau$ in the reaction of Australian ilmenite with sulfuric acid

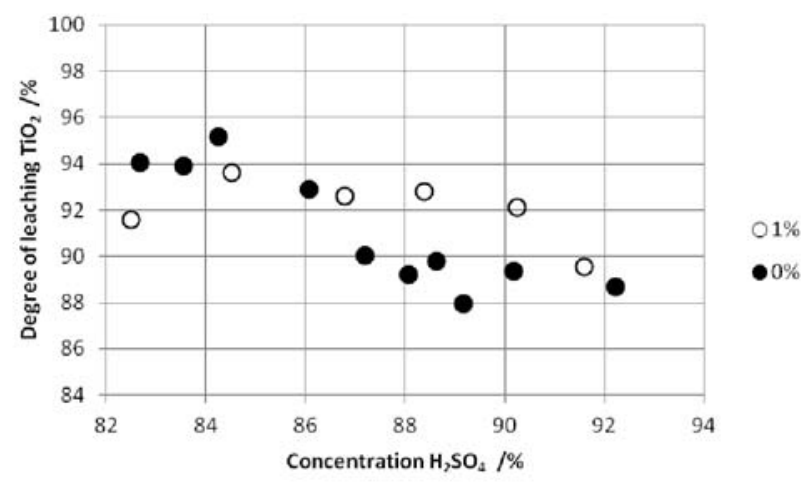

Figure 13. The impact of $1 \%$ sulfur addition on the efficiency of the reaction of Norwegian ilmenites with sulfuric acid

ilmenite. At sulfuric acid concentrations from $82 \%$ to $86 \%$, the differences are slight and within the limit of the measurement error. Above $86 \%$, an increase in the degree of $\mathrm{TiO}_{2}$ leaching is visible in comparison to the reaction without the addition of sulfur. For Australian ilmenite, the situation is slightly different (Fig. 14). At sulfuric acid concentrations from $85 \%$ to $90 \%$, the obtained results are at a similar level and are within the limit of the measurement error. It can be concluded that the addition of sulfur to the reaction environment does not reduce the degree of $\mathrm{TiO}_{2}$ leaching, while in certain concentration ranges improvement of its leaching level is visible. 


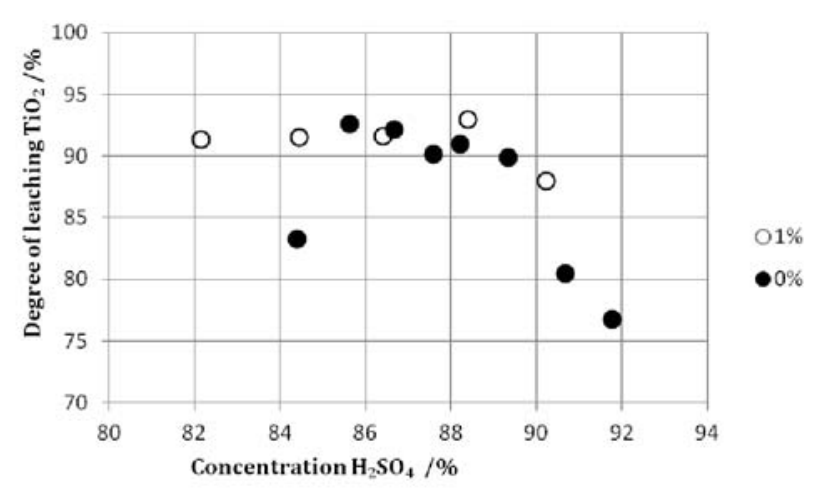

Figure 14. The impact of $1 \%$ sulfur addition on the efficiency of the reaction of Australian ilmenites with sulfuric acid

\section{CONCLUSIONS}

Based on the results of the conducted experiments, it was shown that a small $1 \%$ addition of elemental sulfur significantly affects the thermokinetic parameters of ilmenites reaction with sulfuric acid. The addition of sulfur remarkably reduces the thermal power of the reaction and brings about a substantial decrease in the value of the kinetic parameter $\Delta \mathrm{T}_{\max } / \Delta \tau$. At the same time, the addition of sulfur does not change the quality parameters of raw materials and does not adversely affect the conversion of the substrates. Moreover, the addition of sulfur does not negatively influence the degree of $\mathrm{TiO}_{2}$ leaching; on the contrary, in a certain range of sulfuric acid concentrations, it improves this process. The observed influence of sulfur addition on thermokinetic parameters of the reaction of ilmenites with sulfuric acid is most probably related to the changes in the oxidation degree of sulfur and iron.

The presented results indicate that a small addition of sulfur to the reaction of ilmenites with sulfuric acid may significantly reduce the risk of uncontrolled course of this hazard-type reaction, and thus increase the process safety of titanium dioxide pigment production.

\section{LITERATURE CITED}

1. Johnson, R.W., Audy, S.W. \& Unwin, S.D. (2003). Essential Practices for Managing Chemical Reactivity Hazards. New York: AIChE.

2. Bretherick's Handbook of Reactive Chemical Hazards (P.G. Urben, Ed.). Amsterdam: Academic Press, 2006.

3. OSHA. (2016). Hazard Communication. Hazard Classification Guidance for Manufacturers, Importers, and Employers.

4. Gustin, J.L. (2002). How the study of accident case histories can prevent runaway reaction accidents from recurring. Proc. Safety Environ. Protec., 80, 16-24. DOI: 10.1205/095758202753502370.

5. Fujita, M., Izato, Y., Iizuka, Y. \& Miyake, A. (2019). Thermal hazard evaluation of runaway polymerization of acrylic acid. Proc. Safety Environ. Protec., 129, 339-347. DOI: 10.1016/j.psep.2019.08.003.

6. Casson, V., Lister, D.G., Milazzo, M.F. \& Maschio, G. (2012). Comparison of criteria for prediction of runaway reactions in the sulphuric acid catalyzed esterification of acetic anhydride and methanol. J. Loss Prev. Proc. Ind., 25, 209-217. DOI: 10.1016/j.jlp.2011.09.002.

7. Ni, L., Mebarki, A., Jiang, J., Zhang, M., Pensee, V. \& Dou, Z. (2016). Thermal risk in batch reactors: Theoretical framework for runaway and accident. J. Loss Prev. Proc. Ind., 43, 75-82. DOI: 10.1016/j.jlp.2016.04.004.
8. Sasikumar, C., Rao, D.S., Srikanth, S., Ravikumar, B., Mukhopadhyay, N.K. \& Mehrotra, S.P. (2004). Effect of mechanical activation on the kinetics of sulfuric leaching of beach sand ilmenite from Orissa, India. Hydrometallurgy, 75, 189-204. DOI: $10.1016 \% 2 \mathrm{Fj}$. hydromet.2004.08.001.

9. Liang, B., Li, C., Zhang, C. \& Zhang, Y. (2005). Leaching kinetics of Panzhihua ilmenite in sulfuric acid. Hydrometallurgy, 76, 173-179. DOI: 10.1016\%2Fj.hydromet.2004.10.006.

10. Li, C., Liang, B., Guo, L. \& Wu, Z. (2006). Effect of mechanical activation on the dissolution of Panzhihua ilmenite. Minerals Engineering, 19(14), 1430-1438. DOI: 10.1016/j. mineng.2006.02.005.

11. Greenwood, N.N. \& Earnshaw, A. (1994). Chemistry of the elements. New York: Pergamon Press.

12. Winkler, J. (2003). Titanium Dioxide, Hannover: Vincentz Network.

13. Middlemas, S., Fang, Zak, Z. \& Fan, P. (2013). A new method for production of titanium dioxide pigment. Hydrometallurgy, 131-132, 107-113. DOI: 10.1016/j.hydromet.2012.11.002.

14. Gázquez, M.J., Bolívar, J.P., García-Tenorio, R. \& Vaca, F. (2009). Physicochemical characterization of raw materials and co-products from the titanium dioxide industry. J. Hazard. Mat., 166, 1429-1440. DOI: 10.1016/j.jhazmat.2008.12.067.

15. Zhang, W., Zhu, Z. \& Yong, Cheng, A. (2011). A literature review of titanium metallurgical processes. Hydrometallurgy, 108, 177-188. DOI: 10.1016/j.hydromet.2011.04.005.

16. Mantero, J., Gázquez, M.J., Bolívar, J.P., García-Tenorio, R. \& Vaca, F. (2013). Radioactive characterization of the main materials involved in the titanium dioxide production process and their environmental radiological impact. J. Environ. Radioactivity, 120, 26-32. DOI: 10.1016/j.jenvrad.2013.01.002.

17. Dubenko, A.V., Nikolenko, M.V., Kostyniuk, A. \& Likozar, B. (2020). Sulfuric Acid Leaching of Altered Ilmenite Using Thermal, Mechanical and Chemical Activation. Minerals, 10(6), 538. DOI: 10.3390/min10060538.

18. Dubenko, A.V., Nikolenko, M.V., Kostyniuk, A. \& Likozar, B. (2020). Mechanism, Thermodynamics and Kinetics of Rutile Leaching Process by Sulfuric Acid Reactions. Processes, 8(6), 640. DOI: 10.3390/pr8060640.

19. Moreno, V.C., Kanes, R., Wilday, J. \& Vechot, L. (2015). Modeling of the venting of an untempered system under runaway conditions. J. Loss Prev. Process Ind., 36, 171-182. DOI: 10.1016\%2Fj.jlp.2015.04.016.

20. Lin, C.P., Li, J.S., Tseng, J.M. \& Mannan, M.S. (2016). Thermal runaway reaction for highly exothermic material in safe storage temperature. J. Loss Prev. Proc. Ind. 40, 259-265. DOI: $10.1016 /$ j.jlp.2016.01.006.

21. Parapari, P.S., Irannajad, M. \& Mehdilo, A. (2016). Modification of ilmenite surface properties by superficial dissolution method. Miner. Engin., 92, 160-167. DOI: 10.1016\%2Fj. mineng.2016.03.016.

22. Welham, N.J. \& Llewellyn, D.J. (1998). Mechanical enhancement of the dissolution of ilmenite. Minerals Engineering, 11, 827-841. DOI: 10.1016/S0892-6875(98)00070-3.

23. Yu, J., Chen, L. \& Peng J. (2012). Thermal hazard research smokeless fireworks. J. Thermal Anal. Calorimetry, 109, 1151-1156. DOI: 10.1007/s10973-012-2367-6.

24. El-Sladek, M.H., Ahmed, H.M., El-Barawy, K., Morsi, M.B., El-Didamony, H. \& Bjorkman, B. (2018). Non-isothermal carbothermic reduction kinetics of mechanically activated ilmenite containing self-reducing mixtures. J. Thermal Anal. Calorimetry, 131, 2457-2465. DOI: 10.1007/s10973-017-6743-0.

25. Zheng, F., Guo, Y., Duan, W., Liu, S., Qiu, G., Chen, F., Jiang, T. \& Wang, S. (2018). Transformation of Ti-bearing mineral in Panzhinua electric furnace titanium slag during oxidation roasting process. J. Thermal Anal. Calorimetry, 131, 1767-1776. DOI: 10.1007/s10973-017-6675-8.

26. Jablonski, M., Lawniczak-Jablonska, K. \& Klepka, M.T. (2012). Investigation of phase composition of ilmenites and influence of this parameter on thermokinetics of reaction with 
sulfuric acid. J. Thermal Anal. Calorimetry, 109, 1379-1385. DOI: 10.1007/s10973-011-2136-y.

27. Jablonski, M. \& Tylutka, S. (2016). The influence of initial concentration of sulfuric acid on the degree of leaching of the main elements of ilmenite raw materials. J. Thermal Anal. Calorimetry, 124, 355-361. DOI: 10.1007/s10973-015-5114-y.

28. Jablonski, M. \& Przepiera, A. (2001). Kinetic model for the reaction of ilmenite with sulfuric acid. J. Thermal Anal. Calorimetry, 65, 583-590. DOI: 10.1023/A:1012405826498.
29. Coddell, M. (1959). Analytical chemistry of titanium metals and compounds. New York, Intersciences Publishers Inc.

30. Barin, I. \& Knacke, O. (1973). Thermochemical properties of inorganic substances. Springer-Verlag, Berlin.

31. Jablonski, M. (2009). Influence of particle size distribution on thermokinetics of ilmenite with sulfuric acid reaction. J. Thermal Anal. Calorimetry, 96, 971-977. DOI: 10.1007/ s10973-009-0048-x. 